\title{
Toward Eliminating Discontinuous Yielding Behavior of the EA4T Steel
}

\author{
Jian-Zhi Chen ${ }^{1}$, Qin Du ${ }^{2}$, Guang-Ping Zhang ${ }^{3, *}$ and Bin Zhang ${ }^{2, *}$ \\ 1 Key Laboratory for Anisotropy and Texture of Materials (Ministry of Education), School of Materials Science \\ and Engineering, Northeastern University, 3-11 Wenhua Road, Shenyang 110819, China; jzchen0907@163.com \\ 2 Beijing North Vehicle Group Co. Ltd., 5 Zhujiafenwuli, Beijing 100072, China; duqin12345@sina.com \\ 3 Shenyang National Laboratory for Materials Science, Institute of Metal Research, \\ Chinese Academy of Sciences, 72 Wenhua Road, Shenyang 110016, China \\ * Correspondence: gpzhang@imr.ac.cn (G.-P.Z.); zhangb@atm.neu.edu.cn (B.Z.)
}

check for

updates

Citation: Chen, J.-Z.; Du, Q.; Zhang, G.-P.; Zhang, B. Toward Eliminating Discontinuous Yielding Behavior of the EA4T Steel. Materials 2021, 14 6121. https://doi.org/10.3390/ ma14206121

Academic Editor: Seong-Jun Park

Received: 5 September 2021

Accepted: 12 October 2021

Published: 15 October 2021

Publisher's Note: MDPI stays neutral with regard to jurisdictional claims in published maps and institutional affiliations.

Copyright: (c) 2021 by the authors. Licensee MDPI, Basel, Switzerland. This article is an open access article distributed under the terms and conditions of the Creative Commons Attribution (CC BY) license (https:/ / creativecommons.org/licenses/by/ $4.0 /)$.

\begin{abstract}
Cold-rolled EA4T steel was heat-treated by inter-critical holding at $755^{\circ} \mathrm{C}$ for $90,120,180$, and $240 \mathrm{~s}$, respectively, and then quenching in water. The tensile testing results of the EA4T specimens show an evident transition from the discontinuous yielding to the continuous yielding of the steel specimens by prolonging the holding time. A novel relationship between the discontinuous yielding behavior of tensile-deformed steel specimens and the carbide size was proposed based on experimental results and Cottrell's theory. The model may provide a new clue for avoiding discontinuous yielding and improving mechanical properties of metals with static strain aging behaviors.
\end{abstract}

Keywords: steel; tensile deformation; discontinuous yielding; carbide; heat treatment

\section{Introduction}

Discontinuous yielding (DY), a common behavior occurring in low-carbon steels subjected to tensile deformation, refers to the interaction between the solute atom and the mobile dislocation [1-4]. For the DY, the appearance of yield point elongation (YPE) may be beneficial to resisting strain localization $[5,6]$ and thus improves the strength-ductility combination $[5,7]$. However, the DY behavior can also roughen the product surface $[6,8,9]$, which should be avoided during the thermal processing of metal parts. To avoid the DY of metals, many strategies have been proposed. Among these strategies, a simple and common method is to apply a small pre-strain to the metal before the thermal processing. However, this method is not appropriate for all metals [8], and the pre-strained metals may exhibit the DY again after aging at room temperature for a certain time [10]. In addition, tailoring the heat-treatment process is an effective way to eliminate DY behavior. Effects of carbon concentration $[2,8,9]$, phase content $[8,11]$, grain size $[12,13]$ and other microstructure factors $[5,11,14-16]$ on the DY behavior of metals have been investigated for recent years. An increase of holding time in the heat-treatment process can promote carbide precipitation $[17,18]$ and reduce solute carbon concentration in the matrix, beneficial to prohibiting the DY behavior. However, carbide coarsening and grain growth also occur with increasing the holding time [19-21], and thus degrade the strength of metals. Thus, the optimum holding time for avoiding the DY behavior and keeping superior mechanical properties is a key factor.

EA4T steel (25CrMo4) is a kind of standardized steel used to produce high-speed railway axles, which are required to possess a good combination of strength and ductility $[22,23]$. To obtain finer microstructures and superior mechanical properties, thermal processes such as hot forging are often applied in the manufacturing process of the EA4T axle [24]. Thus, to eliminate the DY phenomena and optimize mechanical properties of EA4T steel, a novel model related to the carbide size and the holding time based on Cottrell's theory was proposed. 


\section{Materials and Methods}

Table 1 presents nominal chemical compositions (in wt. \%) of the EA4T steel studied here. The as-received EA4T steel with tempered sorbite was first held at $910{ }^{\circ} \mathrm{C}$ for $60 \mathrm{~min}$ and quenched in water to room temperature (RT), followed by subsequent tempering at $250^{\circ} \mathrm{C}$ for $180 \mathrm{~min}$ and air cooling. Then, four steel plates with dimensions of $50 \mathrm{~mm} \times 15 \mathrm{~mm} \times 15 \mathrm{~mm}$ cut from the heat-treated EA4T steel plates were cold-rolled with a reduction in the thickness of $80 \%(\varepsilon=186 \%)$. Finally, in order to better study the DY phenomena and optimize the mechanical properties, the cold-rolled plates were intercritical held at $755^{\circ} \mathrm{C}$ for different holding times $(t)$ of $90,120,180$, and $240 \mathrm{~s}$, followed by water quenching to $\mathrm{RT}$ based on the $\mathrm{A}_{1}$ and $\mathrm{A}_{3}$ temperatures $\left(\sim 729^{\circ} \mathrm{C}\right.$ and $\left.\sim 811^{\circ} \mathrm{C}\right)$ of EA4T steel [24] and the theoretical formula of heat-treatment holding time [25].

Table 1. Main chemical compositions of the EA4T steel (wt. \%).

\begin{tabular}{cccccccccc}
\hline $\mathbf{C}$ & $\mathbf{S i}$ & $\mathbf{M n}$ & $\mathbf{S}$ & $\mathbf{P}$ & $\mathbf{C r}$ & $\mathbf{C u}$ & $\mathbf{M o}$ & $\mathbf{N i}$ & $\mathbf{V}$ \\
\hline 0.25 & 0.36 & 0.74 & 0.008 & 0.011 & 1.17 & 0.05 & 0.25 & 0.04 & 0.032 \\
\hline
\end{tabular}

Microstructure observations on the rolling direction (RD)-normal direction (ND) section of specimens were carried out using a scanning electron microscope (SEM, Leo Supra 35, 20 kV, Zeiss Co., Oberkochen, Germany) and a transmission electron microscope (TEM, JEM-2100F, 200 kV, JEOL Co., Tokyo, Japan). Sizes of carbide and martensite were evaluated based on TEM and SEM images. Three dog-bone-shaped specimens with gauge dimensions of $3 \mathrm{~mm} \times 1 \mathrm{~mm} \times 0.25 \mathrm{~mm}$ for each heat-treatment condition were prepared from the steel plates, and then ground mechanically and electro-polished. Uniaxial tensile tests along the RD of specimens were carried out on an INSTRON 5848 Microtester (Instron Co., Norwood, MA, USA) with a strain rate of $1 \times 10^{-3} \mathrm{~s}^{-1}$ at RT, and the tensile strain was measured by a non-contact laser extensometer (MTS LX 300, MTS Co., Minneapolis, MN, USA).

\section{Results and Discussion}

Figure 1a,b show SEM and TEM images of the microstructure after $910{ }^{\circ} \mathrm{C}$ quenching and $250{ }^{\circ} \mathrm{C}$ tempering processes, respectively. The microstructure is mainly composed of lath-like tempered initial martensite (IM). After the $80 \%$ reduction of the cold-rolling process, the severely deformed IM preferentially distributed along the RD, as shown in Figure 1c,d.

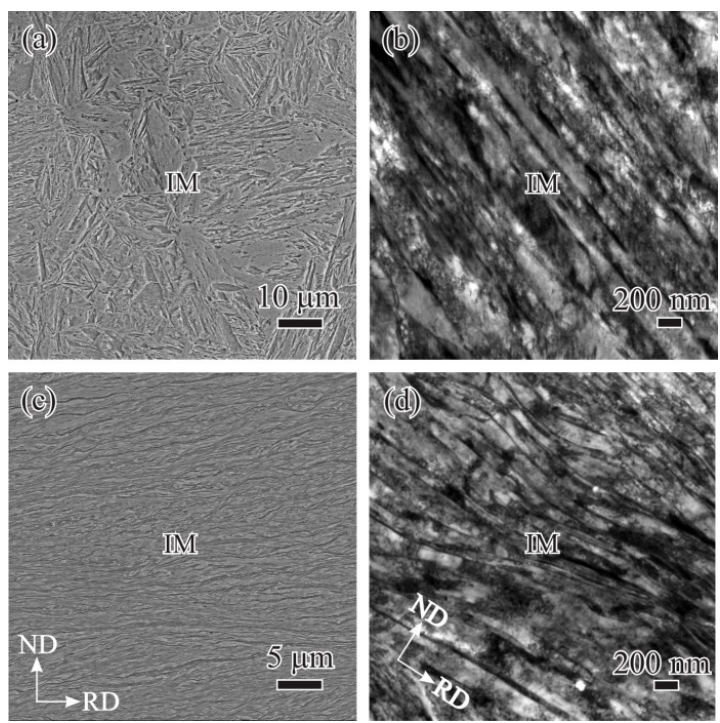

Figure 1. SEM and corresponding TEM images of tempered martensite $(\mathbf{a}, \mathbf{b})$ before and $(\mathbf{c}, \mathbf{d})$ after the cold-rolling. 
After holding at $755{ }^{\circ} \mathrm{C}$ for $t=90 \mathrm{~s}$ and then quenching, the microstructure composed of lamella ferrite regions and IM was obtained, as pointed by white and black arrows in Figure 2a. Ferrite regions contain several lamella ferrite grains parallel to the RD, as circled by the yellow dotted line in Figure 2b. Apart from the lamella ferrite, carbides precipitating at ferrite boundaries could be also observed, as indicated by black arrows shown in Figure 2b. As $t=120 \mathrm{~s}$, lamella ferrite regions and IM remained (Figure 2c), but the ferrite grain in $t=120 \mathrm{~s}$ specimens is wider than that of $t=90 \mathrm{~s}$ specimens by comparing Figure $2 \mathrm{~b}, \mathrm{~d}$. Moreover, the boundaries between the ferrite and the IM are hard to be distinguished, and carbides could be observed inside the ferrite apart from ferrite boundaries, as indicated by the black arrows in Figure 2d.
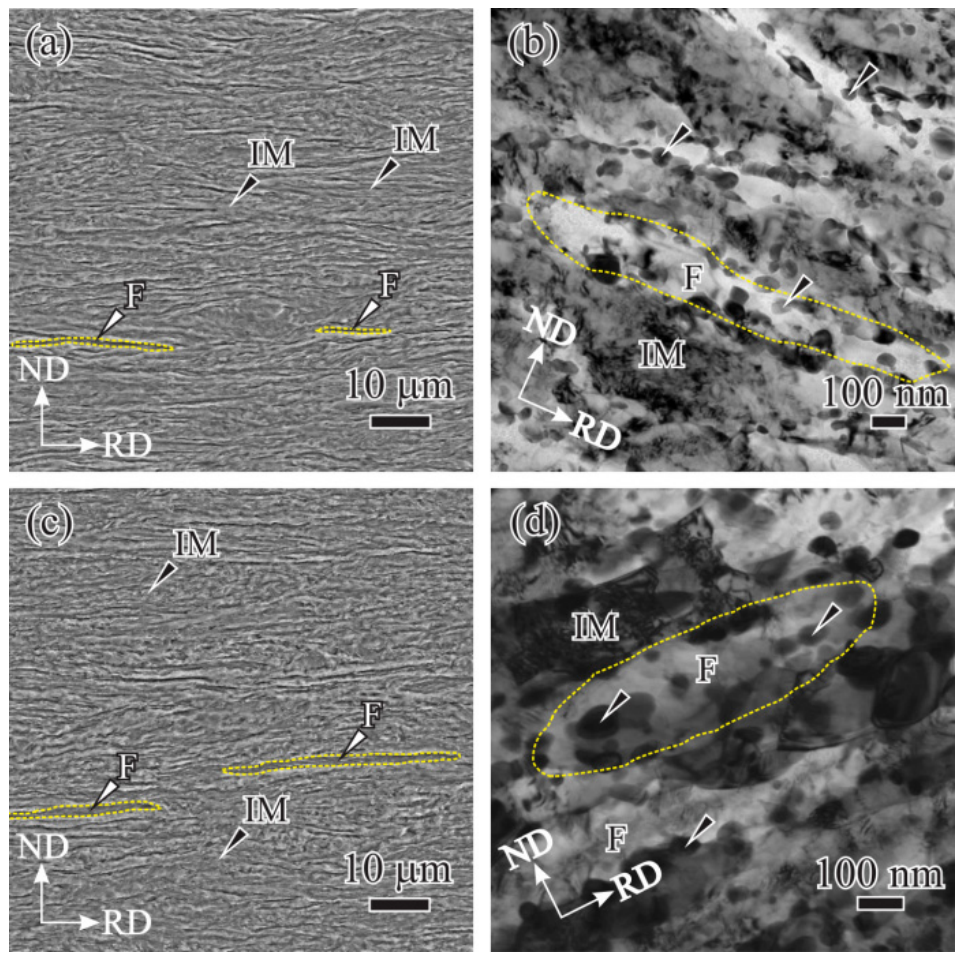

Figure 2. SEM and corresponding TEM images of quenched microstructure after inter-critical holding at $755^{\circ} \mathrm{C}$ for $(\mathbf{a}, \mathbf{b}) 90 \mathrm{~s}$ and $(\mathbf{c}, \mathbf{d}) 120 \mathrm{~s}$.

As $t=180 \mathrm{~s}$, IM was exhausted and replaced by the fresh martensite (FM), the quenching product of austenite generated in the inter-critical holding, the obtained microstructure is consisted of ferrite and FM, as indicated by white and black arrows in Figure 3a. The equiaxed and the lamellar ferrites were observed in the $t=180 \mathrm{~s}$ specimen, as shown by red and blue arrows in Figure 3b. The increasing solid solution carbon released from the exhausted IM promoted the carbide precipitation in surrounding ferrite, thus the volume fraction of carbides $\left(V_{\mathrm{c}}\right)$ increased with prolonging $t$ (see Figures $2 \mathrm{~b}$, d and $3 \mathrm{~b}$ ). As $t$ further increased from $180 \mathrm{~s}$ to $240 \mathrm{~s}$, the size $\left(d_{\mathrm{M}}\right)$ and the volume fraction $\left(V_{\mathrm{M}}\right)$ of FM also increased due to the austenite growth (see Figure $3 \mathrm{a}, \mathrm{c}$ ). In addition to $V_{\mathrm{c}}$, the increase of carbide size $\left(r_{\mathrm{c}}\right)$ due to the Ostwald ripening was also found (see Figures $2 \mathrm{~b}, \mathrm{~d}$ and $3 \mathrm{~b}, \mathrm{~d}$ ). 

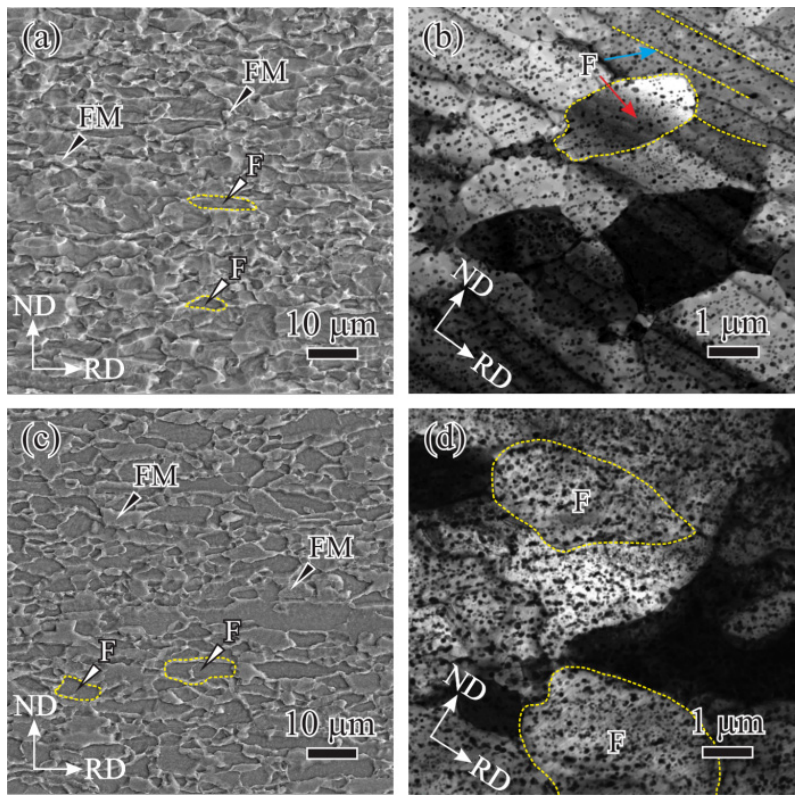

Figure 3. SEM and corresponding TEM images of quenched microstructure after inter-critical holding at $755^{\circ} \mathrm{C}$ for $(\mathbf{a}, \mathbf{b}) 180 \mathrm{~s}$ and $(\mathbf{c}, \mathbf{d}) 240 \mathrm{~s}$.

To reveal the carbide type, the selected area electron diffraction pattern (SAED) of carbide (site A in Figure 4a) along [1] zone axis was obtained (inset of Figure 4a), and the cementite crystal structure was determined. Both $r_{\mathrm{c}}$ and $V_{\mathrm{c}}$ estimated according to TEM images increase with prolonging $t$ (Figure $4 \mathrm{~b}$ ). Continuous release of solute carbon from the IM happened in the inter-critical holding, enhancing the precipitation of carbide. Thus, $V_{\mathrm{c}}$ exhibits an increasing tendency with prolonging $t$, as indicated by a violet line in Figure $4 \mathrm{~b}$. Meanwhile, the Ostwald ripening process driven by the reduction of interfacial energy happened after the carbide precipitation [26-28], and $r_{\mathrm{c}}$ also increases with increasing $t$, as indicated by cyan points in Figure $4 \mathrm{~b}$. Carbon is the controlling element in the Ostwald ripening process, and $r_{\mathrm{c}}$ is generally proportional to $t^{n}$ [29-32]. Thus, $n$ was defined as 0.79 here based on the fitting relationship between $r_{\mathrm{c}}$ and $t$ (cyan dotted line in Figure $4 \mathrm{~b}$ ),
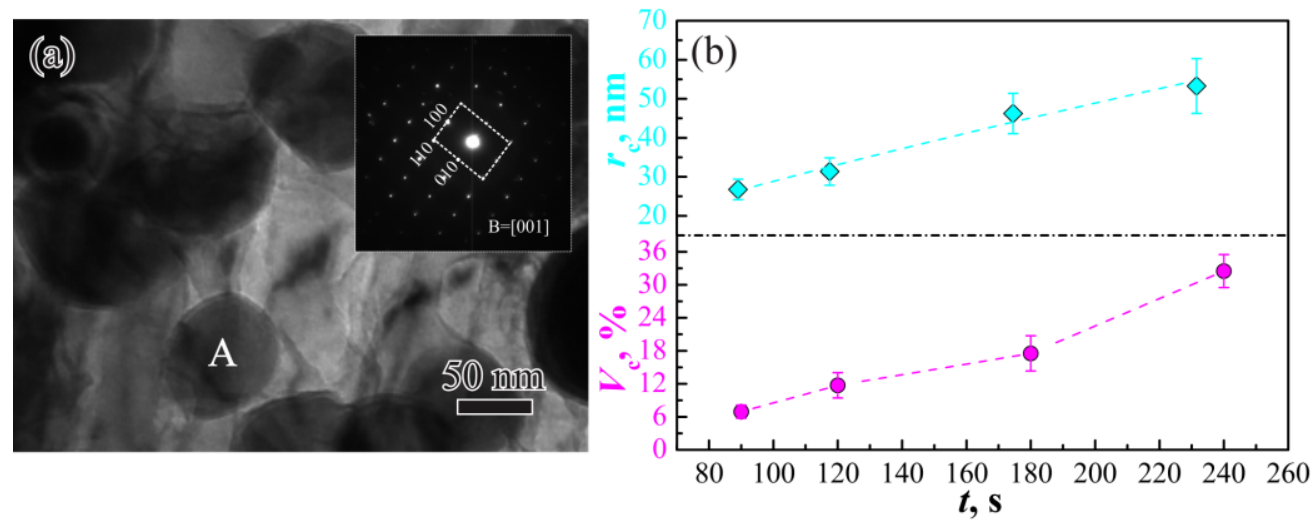

Figure 4. (a) TEM image and selected area electron diffraction of the carbide (Site A); (b) variations of $r_{\mathrm{C}}$ and $V_{\mathrm{c}}$ with $t$.

$$
r_{\mathrm{c}}=2.28+0.69 \times t^{0.79}
$$


In addition, according to the Gibbs-Thompson Equation [33,34], the equilibrium concentration of carbon ( $\left.C_{\alpha \mathrm{rcc}}\right)$ in the matrix can be expressed by Equation (2) when the size of carbide in radius is $r_{c}$,

$$
\mathrm{C}_{\alpha \mathrm{r}_{\mathrm{c}}} \approx \mathrm{C}_{\alpha 0} \cdot\left(1+\frac{2 \gamma \mathrm{V}_{\mathrm{m}}}{\mathrm{C}_{\mathrm{P}} \operatorname{RTr}_{\mathrm{c}}}\right)
$$

Here, $C_{\alpha 0}$ is the equilibrium concentration of carbon in the ferrite matrix when $r_{c}$ is infinite. $\gamma$ is the interfacial energy between the cementite and the matrix, $V_{m}$ is the molar volume of cementite, $C_{\mathrm{P}}$ is the equilibrium molar concentration of carbon in cementite, $R$ and $\mathrm{T}$ are the gas constant and the thermodynamic temperature, respectively. According to Equation (2), one can find that the increase of $r_{c}$ will lead to the decrease of $C_{\alpha r c}$ when other parameters are determined.

Figure 5 a presents engineering stress-strain curves of different specimens, from which variations of tensile strength $\left(\sigma_{\mathrm{b}}\right)$ and total elongation $(\delta)$ with increasing $t$ were obtained, as shown in Figure $5 \mathrm{~b}$. As $t$ is prolonged from $90 \mathrm{~s}$ to $180 \mathrm{~s}, \sigma_{\mathrm{b}}$ decreases but $\delta$ increases. This is mainly caused by the increase of ferrite and the reduction of IM (see Figures 2a,c and 3a). As $t=240 \mathrm{~s}, \sigma_{\mathrm{b}}$ increases but $\delta$ decreases, as compared with that of $t=180 \mathrm{~s}$ specimens. This is mainly related to the increase of FM (see Figure $3 a, c)$. The strength-ductility combination expressed by the product of strength and total elongation (PSE) is shown by the green line in Figure 5b, PSE of specimens increases first and then decreases with prolonging $t$, and the $t=180 \mathrm{~s}$ specimens exhibit the best strength-ductility combination. As $t$ increases from $90 \mathrm{~s}$ to $180 \mathrm{~s}$, PSE shows an increasing tendency, which is mainly related to the increase of ferrite and the recovery of strain hardening capability [5]. Further increasing $t$ from $180 \mathrm{~s}$ to $240 \mathrm{~s}$, the decrease of PSE happened due to the reduction of $\sqrt{V_{\mathrm{M}} / d_{\mathrm{M}}}[35,36]$, $\sim 452 \mathrm{~m}^{-1 / 2}$ for $t=180 \mathrm{~s}$ specimens and $\sim 435 \mathrm{~m}^{-1 / 2}$ for $t=240 \mathrm{~s}$ specimens. To better compare the DY behaviors of different specimens, the upper parts of tensile curves in Figure $5 \mathrm{a}$ are magnified, as shown in Figure $5 \mathrm{c}$. For $t=90 \mathrm{~s}$ and $120 \mathrm{~s}$ specimens, the yielddrop phenomena occur, whereas no YPE appears. The disappearance of YPE is related to the limited volume fraction of ferrite and poor strain hardening capability [37-39]. As $t=180 \mathrm{~s}$, YPE appears after the yield drop due to the increase of ferrite and the recovery of strain hardening capability. On the one hand, as $t=240 \mathrm{~s}$, the increase of the ferrite size is not beneficial to increasing YPE [40]. On the other hand, the increase of $r_{\mathrm{c}}$ can lead to the reduction of carbon in ferrite (Equation (2)), which is also not good for enhancing YPE $[8,14]$. Hence, YPE of the $t=240 \mathrm{~s}$ specimen is lower than that of the $t=180 \mathrm{~s}$ specimen. According to the explanation of DY in the plastic deformation theory, dislocations are immobilized by solute atoms around them. Thus, to generate plastic strain, high stress is required to break dislocations away from the locking effects of the solutes, and therefore the yield drop indicates the immobilized dislocations have broken away from the solute atmosphere [41]. Here, yield-drop stress $\left(\Delta \sigma_{\mathrm{y}}\right)$ expressed by the gap between the upper yield point and the lower yield point $\left(\Delta \sigma_{\mathrm{y}}=\sigma_{\text {upper }}-\sigma_{\text {lower }}\right)$, as indicated by a doubleheaded arrow in Figure $5 c$, was defined to represent the extent of yield drop, one can find that $\Delta \sigma_{\mathrm{y}}$ shows a decreasing trend with prolonging $t$ (Figure $5 \mathrm{~d}$ ).

Generally, DY is related to the pinning effect of the Cottrell atmosphere on the mobile dislocation, and $\Delta \sigma_{\mathrm{y}}$ in DY phenomena is affected by the carbon concentration [2]. The interaction force $(F(\mathrm{r}))$ between the carbon atom and the edge dislocation can be expressed as [42],

$$
F(\mathrm{r})=-\frac{A \sin \theta}{r^{2}}
$$

where $A$ is the material constant. Here, the pinning force between Cottrell atmosphere and dislocation is approximately equal to that between carbon atoms in $l^{2}$ square area (blue area shown in Figure 6) and edge dislocation (red line in Figure 6), $l / 2$ is the mean distance between the carbon atoms and the edge dislocation. Then, according to Equation (3), the mean interaction force $\left(F_{\mathrm{m}}\right)$ between carbon atoms in the blue area and the dislocation is 
equal to $4 A / l^{2}$ when $r=l / 2$ and $\theta=-90^{\circ}$. Therefore, the stress $\left(\sigma_{\mathrm{c}}\right)$ required for the edge dislocation to break away from the Cottrell atmosphere can be obtained [2],

$$
\sigma_{\mathrm{c}}=F_{\mathrm{m}} \cdot l^{2} C_{0} N \exp \left(\frac{l}{\frac{l}{2}}\right) \cdot \frac{1}{b} \approx A_{1} \cdot C_{0}
$$

(a)
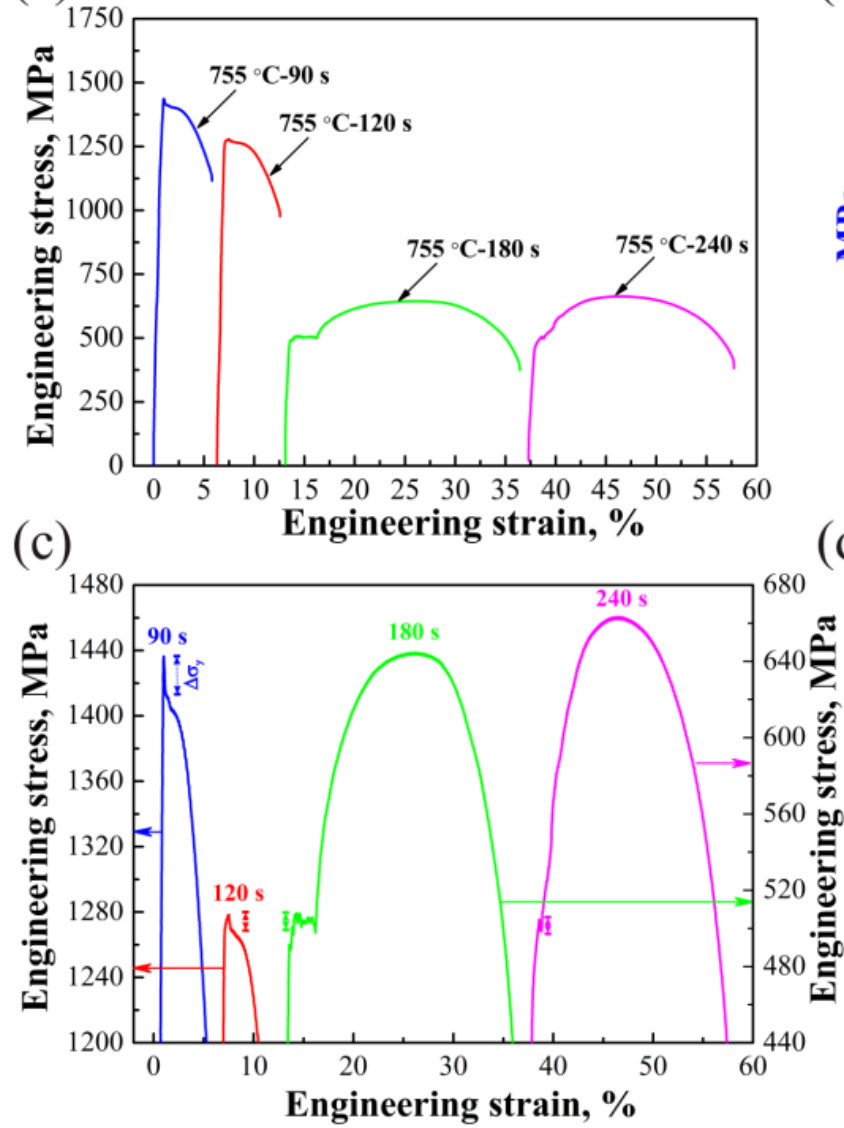

(b)

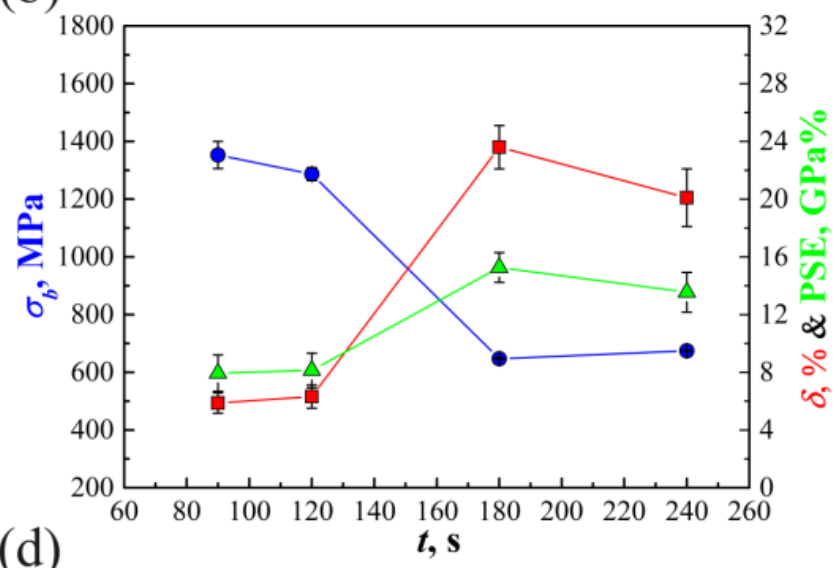

(d)

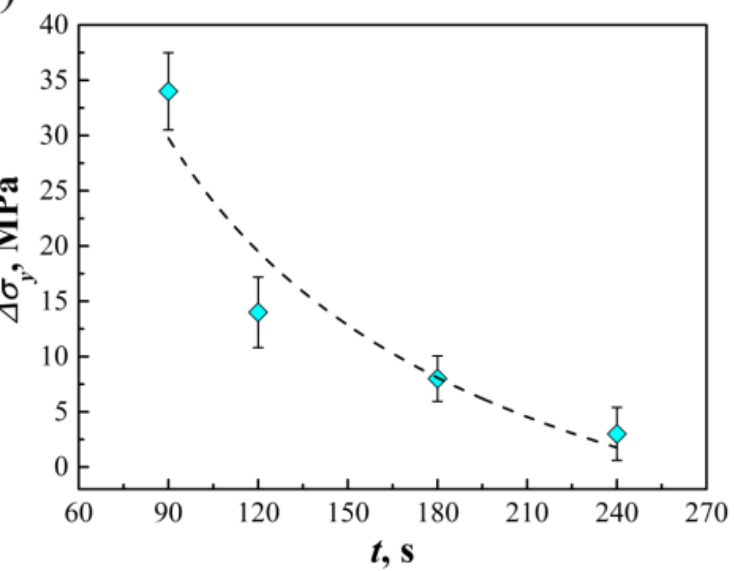

Figure 5. (a) Tensile engineering stress-strain curves; (b) variations of $\sigma_{\mathrm{b}}, \delta$ and PSE with $t$; (c) magnified upper parts of tensile curves; (d) relationship between $\Delta \sigma_{\mathrm{y}}$ and $t$.

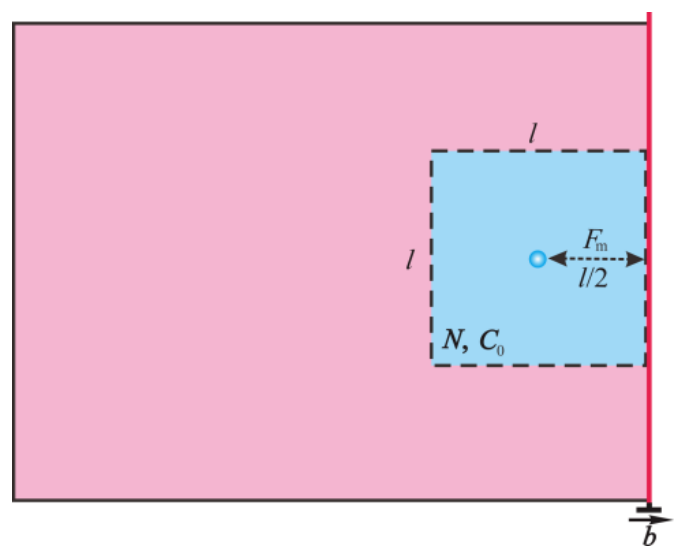

Figure 6. Schematic diagram of the interaction between the dislocation and the Cottrell atmosphere. 
$C_{0}$ is the equilibrium carbon concentration, $N$ is the total number of atoms in unit volume, $b$ is the Burgers vector, and $A_{1}$ is a material constant. Let $C_{0}=C_{\alpha \mathrm{rc}}, \Delta \sigma_{\mathrm{y}}=\sigma_{\mathrm{c}}$, one can obtain a model of Equation (5) by substituting Equation (2) into Equation (4),

$$
\sigma_{\mathrm{y}}=A_{1} \cdot C_{\alpha 0} \cdot\left(1+\frac{2 \gamma V_{\mathrm{m}}}{C_{\mathrm{P}} R T r_{\mathrm{c}}}\right)=B+\frac{\mathrm{C}}{r_{\mathrm{c}}}
$$

where both $B$ and $C$ are material constants. Substituting Equation (1) into Equation (5), the relationship between $\Delta \sigma_{\mathrm{y}}$ and $t$ in Figure $5 \mathrm{~d}$ can be fitted as,

$$
\sigma_{y}=-24.43+\frac{1431.57}{r_{c}}=-24.43+\frac{1431.57}{2.28+0.69 \times t^{0.79}}
$$

Let $\Delta \sigma_{\mathrm{y}}=0$ in Equation (6), then, $r_{\mathrm{c}} \approx 59 \mathrm{~nm}$ and $t \approx 265 \mathrm{~s}$ are attained. Hence, to avoid the DY behavior, a condition with $r_{\mathrm{c}} \geq 59 \mathrm{~nm}$ and $t \geq 265 \mathrm{~s}$ should be satisfied. Moreover, as shown in Figure $5 \mathrm{~b}$, the PSE values decrease when $t>180 \mathrm{~s}$, indicating the deterioration of the strength-ductility combination. Therefore, to avoid DY behaviors and keep a better strength-ductility combination of the EA4T steel, one can obtain $r_{\mathrm{c}} \approx 59 \mathrm{~nm}$ according to Equation (6), corresponding to $t \approx 265 \mathrm{~s}$. To confirm the disappearance of discontinuous yielding at $t \geq 265 \mathrm{~s}$, the tensile test of the specimen after inter-critical holding at $755^{\circ} \mathrm{C}$ for $300 \mathrm{~s}$ and quenching was carried out. Figure 7a presents the tensile curve. $\sigma_{\mathrm{b}}$ and the $\delta$ are $656.59 \mathrm{MPa}$ and $17.02 \%$ respectively, and the PSE is $11.18 \mathrm{GPa} \%$, which is lower than $t=240 \mathrm{~s}$ specimens (Figure $5 \mathrm{~b}$ ). The yielding zone surrounded by the red rectangle in Figure 7a is magnified and shown in Figure 7b. One can find that the yield-drop phenomenon disappears, which confirms the reliability of the model.
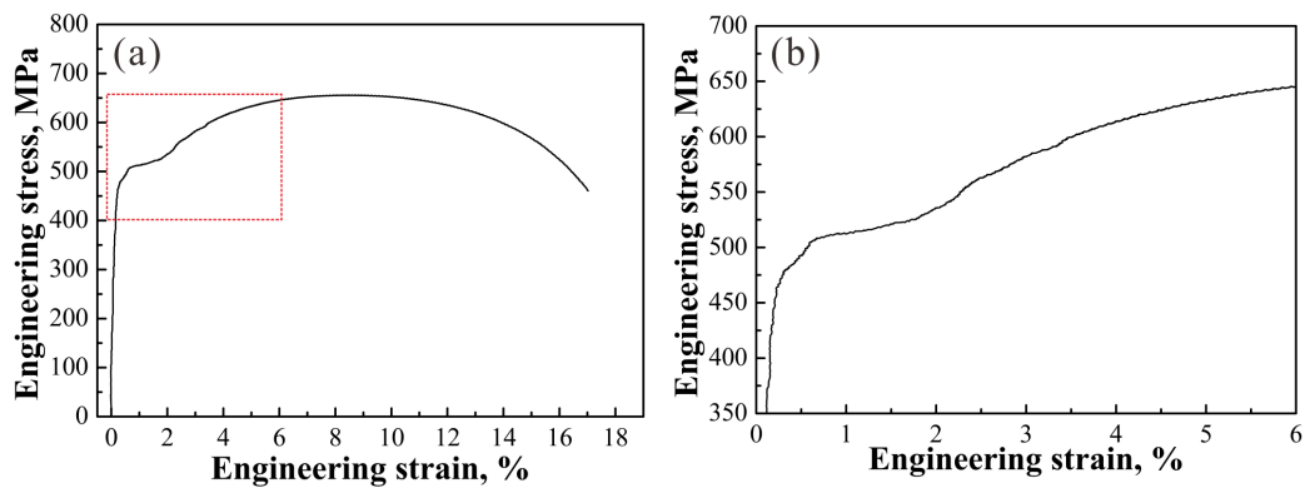

Figure 7. (a) Tensile engineering stress-strain curve and (b) magnified yielding zone of the specimen after inter-critical holding at $755^{\circ} \mathrm{C}$ for $300 \mathrm{~s}$ and quenching.

Generally, the finer and more dispersed carbides are beneficial to improving mechanical properties of metals. However, for the metals with static strain aging behavior, the decrease of $r_{\mathrm{c}}$ will enhance $\Delta \sigma_{\mathrm{y}}$, promoting undesirable DY behavior. A proper increase of $r_{\mathrm{c}}$ with prolonging $t$ can help to change the tensile curve from the discontinuous yielding to the continuous yielding, thus, it is expected that the optimum $t$ for the metals with continuous yielding and relatively superior mechanical properties can be achieved by tailoring $r_{\mathrm{c}}$ in the model of Equation (5).

\section{Conclusions}

In summary, by examining tensile stress-strain responses of the EA4T steel specimens subjected to inter-critical holding and quenching, an evident transition from the discontinuous yielding type to the continuous yielding type of tensile curves was observed with increasing holding time. A novel model related to the DY behavior was proposed based on the experimental results and Cottrell's theory. The critical carbide size $\left(r_{\mathrm{c}}=59 \mathrm{~nm}\right)$ and the holding time ( $t=265 \mathrm{~s})$ of the EA4T steel corresponding to continuous yield- 
ing and relatively superior strength-ductility combination were derived according to the model. It is expected that the model may be used to inhibit DY behaviors and improve the strength-ductility combination of other metals with static strain aging behaviors.

Author Contributions: Conceptualization, G.-P.Z. and B.Z.; methodology, Q.D.; validation, Q.D.; formal analysis, J.-Z.C. and Q.D.; investigation, J.-Z.C.; resources, G.-P.Z.; data curation, J.-Z.C.; writing-original draft preparation, J.-Z.C.; writing-review and editing, G.-P.Z. and B.Z.; supervision, G.-P.Z.; project administration, B.Z.; funding acquisition, G.-P.Z. and B.Z. All authors have read and agreed to the published version of the manuscript.

Funding: The project was funded by the National Natural Science Foundation of China (NSFC, Grant Nos. 51971060 and 51771207).

Institutional Review Board Statement: Not applicable.

Informed Consent Statement: Not applicable.

Data Availability Statement: Data sharing is not applicable for this article.

Conflicts of Interest: The authors declare no conflict of interest.

\section{References}

1. Cottrell, A.H.; Bilby, B.A. Dislocation theory of yielding and strain aging of iron. Proc. Phys. Soc. 1949, 62, 49-62. [CrossRef]

2. Cottrell, A.H. Dislocations and Plastic Flow in Crystals, 1st ed.; Clarendon Press: Oxford, UK, 1956.

3. Bilby, B.A. On the interactions of dislocations and solute atoms. Proc. Phys. Soc. 1950, 63, 191-200. [CrossRef]

4. Nakamura, A.; Matsunaga, K.; Tochigi, E.; Shibata, N.; Ikuhara, Y.; Lagerlö, K.P.D. Another origin of yield drop behavior in sapphire deformed via basal slip: Recombination of climb-dissociated partial dislocations. Scr. Mater. 2017, 138, 109-113. [CrossRef]

5. Gao, S.; Bai, Y.; Zheng, R.; Tian, Y.; Mao, W.; Shibata, A.; Tsuji, N. Mechanism of huge Lüders-type deformation in ultrafine grained austenitic stainless steel. Scr. Mater. 2019, 159, 28-32. [CrossRef]

6. Wang, X.G.; Wang, L.; Huang, M.X. Kinematic and thermal characteristics of Lüders and Portevin-Le Châtelier bands in a medium Mn transformation-induced plasticity steel. Acta Mater. 2017, 124, 17-29. [CrossRef]

7. Sun, G.S.; Du, L.X.; Hu, J.; Misra, R.D.K. Microstructural evolution and recrystallization behavior of cold rolled austenitic stainless steel with dual phase microstructure during isothermal annealing. Mater. Sci. Eng. A 2018, 709, 254-264. [CrossRef]

8. Luo, H.; Dong, H.; Huang, M. Effect of intercritical annealing on the Lüders strains of medium Mn transformation-induced plasticity steels. Mater. Des. 2015, 83, 42-48. [CrossRef]

9. Emadoddin, E.; Akbarzadeh, A.; Daneshi, G.H. Correlation between Luder strain and retained austenite in TRIP-assisted cold rolled steel sheets. Mater. Sci. Eng. A 2007, 447, 174-179. [CrossRef]

10. Wang, Y.; Tomota, Y.; Ohmura, T.; Gong, W.; Harjo, S.; Tanaka, M. Continuous and discontinuous yielding behaviors in ferrite-cementite steels. Acta Mater. 2020, 196, 565-575. [CrossRef]

11. Kim, D.H.; Kang, J.H.; Ryu, J.H.; Kim, S.J. Effect of austenitization of cold-rolled 10 wt. \% Mn steel on microstructure and discontinuous yielding. Mater. Sci. Eng. A 2020, 774, 138930. [CrossRef]

12. Zhao, M.C.; Yin, F.X.; Hanamura, T.; Nagai, K.; Atrens, A. Relationship between yield strength and grain size for a bimodal structural ultrafine-grained ferrite/cementite steel. Scr. Mater. 2007, 57, 857-860. [CrossRef]

13. Tian, Y.Z.; Gao, S.; Zhao, L.J.; Lu, S.; Pippan, R.; Zhang, Z.F.; Tsuji, N. Remarkable transitions of yield behavior and Lüders deformation in pure $\mathrm{Cu}$ by changing grain sizes. Scr. Mater. 2018, 142, 88-91. [CrossRef]

14. Tsuchida, N.; Tomota, Y.; Nagai, K.; Fukaura, K. A simple relationship between Lüders elongation and work-hardening rate at lower yield stress. Scr. Mater. 2006, 54, 57-60. [CrossRef]

15. Fu, L.; Li, Z.; Wang, H.; Wang, W.; Shan, A. Lüders-like deformation induced by delta-ferrite-assisted martensitic transformation in a dual-phase high-manganese steel. Scr. Mater. 2012, 67, 297-300. [CrossRef]

16. Ma, J.; Liu, H.; Lu, Q.; Zhong, Y.; Wang, L.; Shen, Y. Transformation kinetics of retained austenite in the tensile Lüders strain range in medium Mn steel. Scr. Mater. 2019, 169, 1-5. [CrossRef]

17. Ju, Y.; Goodall, A.; Strangwood, M.; Davis, C. Characterisation of precipitation and carbide coarsening in low carbon low alloy Q\&T steels during the early stages of tempering. Mater. Sci. Eng. A 2018, 738, 174-189. [CrossRef]

18. Janovec, J.; Svoboda, M.; Výrostková, A.; Kroupa, A. Time-temperature-precipitation diagrams of carbide evolution in low alloy steels. Mater. Sci. Eng. A 2005, 402, 288-293. [CrossRef]

19. Maalekian, M.; Radis, R.; Militzer, M.; Moreau, A.; Poole, W.J. In situ measurement and modeling of austenite grain growth in a $\mathrm{Ti} / \mathrm{Nb}$ microalloyed steel. Acta Mater. 2012, 60, 1015-1026. [CrossRef]

20. Kwon, Y.; Zargaran, A.; Ryu, J.H.; Kim, N.J. Effect of annealing conditions on the microstructure and tensile properties of $0.5 \mathrm{~V}$ containing Fe-16Mn-0.8C-0.5Si steel. Scr. Mater. 2019, 172, 125-129. [CrossRef] 
21. Natori, M.; Futamura, Y.; Tsuchiyama, T.; Takaki, S. Difference in recrystallization behavior between lath martensite and deformed ferrite in ultralow carbon steel. Scr. Mater. 2005, 53, 603-608. [CrossRef]

22. Xu, Z.W.; Wu, S.C.; Wang, X.S. Fatigue evaluation for high-speed railway axles with surface scratch. Int. J. Fatigue 2019, 123, 79-86. [CrossRef]

23. Fintová, S.; Pokorný, P.; Fajkoš, R.; Hutař, P. EA4T railway axle steel fatigue behavior under very high-frequency fatigue loading. Eng. Failure Anal. 2020, 115, 104668. [CrossRef]

24. Wang, Z.S.; Liang, Y.L.; Wu, S.B.; Liang, Y.; Wang, X. Effect of tempering process on microstructure and properties of EA4T axle steel. Trans. Mater. Heat Treat. 2012, 33, 48-52. [CrossRef]

25. Heat Treatment Society of China Society of Mechanical Engineering. Heat Treatment Manual_Process Basis, 4th ed.; China Machine Press: Beijing, China, 2008; pp. 42-43. (In Chinese)

26. Björklund, S.; Donaghey, L.F.; Hillert, M. The effect of alloying elements on the rate of Ostwald ripening of cementite in steel. Acta Metall. 1972, 20, 867-874. [CrossRef]

27. Bellare, A.; Dadyburjor, D.B. Effect of the size dependence of particle diffusion and surface tension on the sintering of supported metal catalysts. AIChE J. 1987, 33, 867-870. [CrossRef]

28. Zhao, M.C.; Hanamura, T.; Hai, Q.; Nagai, K.; Ke, Y. Grain growth and Hall-Petch relation in dual-sized ferrite/cementite steel with nano-sized cementite particles in a heterogeneous and dense distribution. Scr. Mater. 2006, 54, 1193-1197. [CrossRef]

29. Lifshitz, I.M.; Slyozov, V.V.J. The kinetics of precipitation from supersaturated solid solutions. J. Phys. Chem. Solids 1961, 19, 35-50. [CrossRef]

30. Ardell, A.J. The effect of volume fraction on particle coarsening: Theoretical considerations. Acta Metall. 1972, 20 , 61-71. [CrossRef]

31. Zhao, Y.Y.; Chen, H.W.; Lu, Z.P.; Nieh, T.G. Thermal stability and coarsening of coherent particles in a precipitation-hardened (NiCoFeCr)94Ti2Al4 high-entropy alloy. Acta Mater. 2018, 147, 184-194. [CrossRef]

32. Ardell, A.J. Quantitative predictions of the trans-interface diffusion-controlled theory of particle coarsening. Acta Mater. 2010, 58, 4325-4331. [CrossRef]

33. Moon, J.; Lee, C.; Uhm, S.; Lee, J. Coarsening kinetics of TiN particle in a low alloyed steel in weld HAZ: Considering critical particle size. Acta Mater. 2006, 54, 1053-1061. [CrossRef]

34. Li, X.; Thornton, K.; Nie, Q.; Voorhees, P.W.; Lowengrub, J.S. Two- and three-dimensional equilibrium morphology of a misfitting particle and the Gibbs-Thomson effect. Acta Mater. 2004, 52, 5829-5843. [CrossRef]

35. Alibeyki, M.; Mirzadeh, H.; Najafi, M. Fine-grained dual phase steel via intercritical annealing of cold-rolled martensite. Vacuum 2018, 155, 147-152. [CrossRef]

36. Balliger, N.K.; Gladman, T. Work hardening of dual-phase steels. Met. Sci. J. 1981, 15, 95-108. [CrossRef]

37. Huang, X.; Hansen, N.; Tsuji, N. Hardening by annealing and softening by deformation in nanostructured metals. Science 2006, 312, 249-251. [CrossRef]

38. Estrin, Y.; Vinogradov, A. Extreme grain refinement by severe plastic deformation: A wealth of challenging science. Acta Mater. 2013, 61, 782-817. [CrossRef]

39. Yu, C.Y.; Kao, P.W.; Chang, C.P. Transition of tensile deformation behaviors in ultrafine-grained aluminum. Acta Mater. 2005, 53, 4019-4028. [CrossRef]

40. Butler, J.F. Lüders front propagation in low carbon steels. J. Mech. Phys. Solids 1962, 10, 313-318. [CrossRef]

41. Kim, W.J.; Jeong, H.T. Pronounced yield drop phenomenon at high temperatures in Al-Mg alloys with high contents of Mg (5-13 wt. \%). Mater. Sci. Eng. A 2019, 743, 590-596. [CrossRef]

42. Ehrenreich, H.; Hirth, J.P. Mechanism for dislocation density reduction in GaAs crystals by indium addition. Appl. Phys. Lett. 1985, 46, 668-670. [CrossRef] 